\title{
LATERAL ANKLE LIGAMENT COMPLEX SPRAIN - EPIDEMIOLOGY IN THE POPULATION OF THE VARNA REGION
}

\author{
Preslav Penev \\ "St. Anna" University Hospital, Department of Orthopedics and Traumatology
}

\begin{abstract}
INTRODUCTION: Ankle sprains are a very common injury, not only in sports, but also in everyday life. This pattern has been studied in athletics, but little is known of its epidemiology in the general population. We have not determined the epidemiology rate of an ankle sprain in the Bulgarian population specifically in the Varna region after 1990. Because of this, we have used a longterm, retrospective epidemiological database to determine the incidence of ankle sprains admitted in the Emergency Trauma Center - University Hospital „St. Anna“ - Varna, Bulgaria.

MATERIAL AND METHODS: We have performed a retrospective statistical processing of patients who have passed through the Emergency trauma center during the period 01.01.2014 31.12.2014. The incidence rate ratios were then calculated with respect to age, sex, and the involvement of the medial or lateral ankle aspect.

RESULTS: During the study period, an estimated 1267 ankle sprains occurred among a population of 475074 (2011) in the Varna region. The epidemiological rate for this period is $2.46 \%$. The gender distribution - male/female ratio was $1.2 / 1(\delta 609, q 560)$. The lateral ankle ligament complex sprains were $92.26 \%$ (1169 cases) of all ankle sprains.

CONCLUSION: Ankle sprains occur with a high frequency. They significantly affect the lateral ligament complex. The injury occurs not only during sports, but in everyday life as well. The ankle sprains are often misdiagnosed and undertreated, resulting in chronic pain, muscular weakness and instability. This common trauma leads to serious socio-economic consequences because it requires a long-term recovery, followed by physical therapy.
\end{abstract}

Keywords: ankle sprain, retrospective statistical processing, lateral ankle aspect, medial ankle aspect

Address for correspondence:

Preslav Penev

98A, Patriarh Evtimii Str., ap. 1

9000 Varna, Bulgaria

e-mail:dr_penev@abv.bg

Received: April 4, 2015

Accepted: August 21, 2015

\section{INTRODUCTION}

The lateral ankle ligament complex consists of the anterior talofibular ligament (ATFL), the calcaneofibular ligament (CFL), and the posterior talofibular ligament (PTFL). The ATFL is the weakest of the lateral collateral ligaments and therefore the first to be injured (1).This ligament is involved in practically all lateral ankle sprains. Lateral ankle ligament inju- 
ries are graded from I to III) (2). In a grade I sprain: - slight stretching and some damage to the fibres of the ligament. A grade II sprain involves partial tearing of the ATFL. A grade III injury implies complete damaging of the ATFL (Fig. 1). The most common mechanism of injury is inversion, plantar flexion, and internal rotation. The ankle sprain is one of the most common injuries and can happen to athletes and non-athletes, children and adults. Some studies have shown that the incidence of ankle sprains is between 3 and 5\% of all Emergency Department visits (3). In the UK, an estimated 302,000 ankle sprains are seen each year in the Accident and Emergency Departments (4). There is not any database for ankle sprain epidemiology in Bulgaria after 1990. We aim to determine the epidemiological incidence of ankle sprains, notably in the population of the Varna region. Indicated will be the significance of the disease in terms of gender, age and financial aspects.

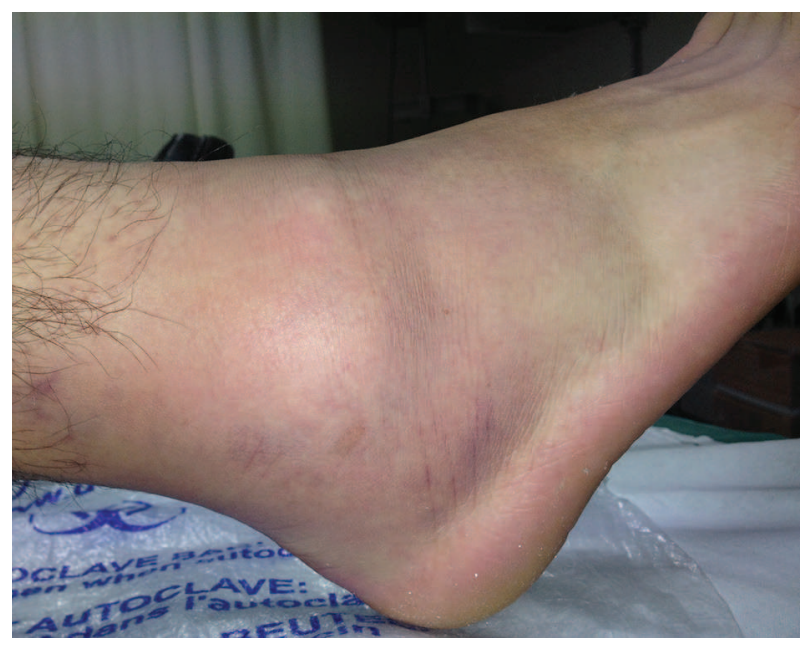

Fig. 1. III grade ankle sprain

\section{MATERIALS AND METHODS}

The population is largely served by only one Emergency Trauma Center. Our dataset is supplied from this unit. The cases included were defined as a first attendance at the Emergency Trauma Center between 01.01.2014 and 31.12.2014, and having a diagnostic code of ankle sprain. Incidence rates were calculated as the number of ankle sprains, divided by the resident population using the most recently available population estimates from the National Statistical Institute. We could not include the ankle sprains that have not sought emergency car or have been treated by the GPs. We have performed a retrospective statistical processing of the patients and we have had the opportunity to collect data every month.

\section{RESULTS}

The population in the Varna region is 475074 (2011) according to the National Statistical Institute (5). A retrospective study for a period of one year between 01.01.2014 and 31.12.2014, involved 18632 patients, who visited the Emergency Trauma Center at the University Hospital „St. Anna“ - Varna, Bulgaria. We have recorded 1267 new cases of ankle sprains. The incidence rate of all ankle sprains in the population of the Varna region is $6.8 \% .1169$ patients $(92.26 \%)$ have had lateral sprains and only 98 (7.73\%) - medial sprains. Lateral ankle ligament complex sprains are presented in $6.27 \%$ of all emergency and trauma patients. There has been III Grade sprain with acute lateral instability in 68 cases $(5.81 \%$ of patients with lateral ankle ligament complex sprain). The instability was demonstrated by ultrasound or stress radiography. The epidemiological rate in the population of the Varna for 2014 is $2.46 \%$ o. There were marked age - sex differences (Table 1). For the estimated ankle sprains with available sex classification, males accounted for 609 (52\%) and females accounted for 560 (48\%).

The mean patient age was 25.40 years. The peak incidence of ankle sprains occurred between fifteen and twenty years of age (Fig. 2). A total of $21.72 \%$ of all injuries were lateral ankle sprains in children, $27.88 \%$ in adolescents and $50.38 \%$ in adults. This study demonstrated that younger patients are more likely to be injured.

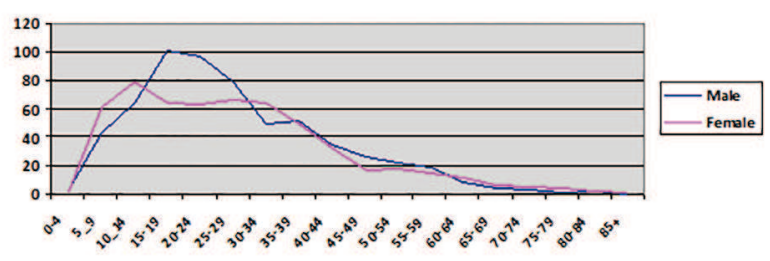

Fig. 2. Age-sex specific rates of ankle sprain attendance

\section{DISCUSSION}

This study is the first we are aware of, based in the Varna region, that tries to quantify the inci- 
Table 1. Numbers and rates of ankle sprain by age (years) and sex

\begin{tabular}{lcccc|c|c|c|c|c} 
Age range & $\begin{array}{c}\text { Population } \\
- \text { Male }\end{array}$ & Ls - Male & Rate Male & $\begin{array}{c}\text { Population } \\
- \text { Female }\end{array}$ & $\begin{array}{c}\text { Ls - Fe- } \\
\text { male }\end{array}$ & $\begin{array}{c}\text { Rate } \\
\text { Female }\end{array}$ & $\begin{array}{c}\text { Total } \\
\text { Popula- } \\
\text { tion }\end{array}$ & Ls - All & Total Rate \\
\hline Total & $\mathbf{2 3 2} \mathbf{6 2 7}$ & 609 & $2,61 \%$ & 242447 & 560 & $2,30 \%$ & 475074 & 1169 & $\mathbf{2 , 4 6}$ \\
$\mathbf{0 - 4}$ & 13008 & 3 & 0.23 & 12264 & 2 & 0.16 & 25272 & 5 & 0.19 \\
$\mathbf{5 - 9}$ & 11072 & 44 & 3.97 & 10345 & 61 & 5.89 & 21417 & 105 & 4.9 \\
$\mathbf{1 0 - 1 4}$ & 10432 & 65 & 6.23 & 10142 & 79 & 7.78 & 20574 & 144 & 6.99 \\
$\mathbf{1 5 - 1 9}$ & 12113 & 101 & 8.33 & 11448 & 65 & 5.67 & 23561 & 166 & 7.04 \\
$\mathbf{2 0 - 2 4}$ & 17318 & 97 & 5.6 & 16693 & 63 & 3.77 & 34011 & 160 & 4.7 \\
$\mathbf{2 5 - 2 9}$ & 18600 & 79 & 4.24 & 17952 & 67 & 3.73 & 36552 & 146 & 3.99 \\
$\mathbf{3 0 - 3 4}$ & 20354 & 50 & 2.45 & 19155 & 65 & 3.39 & 39509 & 115 & 2.91 \\
$\mathbf{3 5 - 3 9}$ & 20419 & 52 & 2.54 & 18975 & 50 & 2.63 & 39394 & 102 & 2.58 \\
$\mathbf{4 0 - 4 4}$ & 17397 & 34 & 1.95 & 16045 & 32 & 1.99 & 33442 & 66 & 1.97 \\
$\mathbf{4 5 - 4 9}$ & 15347 & 26 & 1.69 & 15237 & 16 & 1.05 & 30584 & 42 & 1.37 \\
$\mathbf{5 0 - 5 4}$ & 15149 & 22 & 1.45 & 15512 & 17 & 1.09 & 30661 & 39 & 1.27 \\
$\mathbf{5 5 - 5 9}$ & 15247 & 18 & 1.18 & 16727 & 14 & 0.83 & 31974 & 32 & 1 \\
$\mathbf{6 0 - 6 4}$ & 14782 & 8 & 0.54 & 17190 & 11 & 0.63 & 31972 & 19 & 0.59 \\
$\mathbf{6 5 - 6 9}$ & 10921 & 4 & 0.36 & 13486 & 6 & 0.44 & 24407 & 10 & 0.4 \\
$\mathbf{7 0 - 7 4}$ & 8166 & 3 & 0.36 & 11116 & 5 & 0.44 & 19282 & 8 & 0.41 \\
$\mathbf{7 5 - 7 9}$ & 6466 & 1 & 0.15 & 10129 & 4 & 0.39 & 16595 & 5 & 0.3 \\
$\mathbf{8 0 - 8 4}$ & 3928 & 2 & 0.5 & 6444 & 2 & 0.31 & 10372 & 4 & 0.38 \\
$\mathbf{8 5}+$ & 1908 & 0 & 0 & 3587 & 1 & 0.27 & 5495 & 1 & 0.18 \\
\hline
\end{tabular}

dence of ankle sprains and severe ankle sprains being attended to at the Emergency Trauma Center at the University Hospital „St. Anna“ - Varna for a geographical population. Based on our study, we estimate that there are 1169 new lateral ligament ankle sprains in the Varna region every year. According to the stress tests, ultrasound or stress radiography, there were found I, II and III types of sprain. Following these findings, different treatment approaches were applied: in type I - 7 days of soft bandage; in type II - 15 days of plastic orthosis; in type III (complete tear) - 25 days of plaster immobilization or operative treatment.

Ankle sprain has high socio-economic costs associated with the diagnosis, treatment and loss of work productivity contingent with the severity of injury. The costs of individual treatments are variable. If all lateral ligament ankle sprains are considered to be type I and treated 7 days with a soft immobilization and 7 days physiotherapy, the cost for each pa- tient at an average wage of 812 lev will be worth 546 lev.

\section{CONCLUSION}

Lateral ankle sprains account for $6.27 \%$ of all emergency and trauma patients. This common injury is most frequently sustained during sport activity but also in everyday life. The ATFL is the weakest of the lateral ankle ligament complex. The consequence of this common injury for patients is days lost in work, missed due to injury as well as the cost of rehabilitation.

\section{REFERENCES}

1. Reid DC. Sports injury assessment and rehabilitation. New York: Churchill Livingston Inc.; 1992. p. 215-68.

2. Chorley JN, Hergenroeder AC. Management of ankle sprains. Pediatr Ann 1997;26(1): 56-64. 
Lateral Ankle Ligament Complex Sprain - Epidemiology in the Population of the Varna Region

3. Ferran NA; Epidemiology of sprains of the lateral ankle ligament complex - Foot Ankle Clin - 01SEP-2006; 11(3): 659-62

4. Cailbhe Doherty, Eamonn Delahunt, Brian Caulfield, Jay Hertel, John Ryan, Chris Bleakley; The Incidence and Prevalence of Ankle Sprain Injury: A Systematic Review and Meta-Analysis of Prospective Epidemiological Studies; Sports Med DOI 10.1007/s40279-013-0102-5

5. http://www.nsi.bg/bg 